\title{
O PAPEL DA VÍTIMA NO PROCESSO PENAL
}

\author{
Antonio Milton de Barros \\ Professor de Processo Penal, na Faculdade de Direito de Franca \\ Pós-graduado "Lato Sensu”, em Direito Penal e Processo Penal, pela FDF \\ Especialista em Processo Penal, pela Universidadede Salamanca - Espanha, \\ Mestre e doutor em Processo Penal pela PUC - SP, \\ Fundador e orientador do Núcleo de Aperfeiçoamento e Crítica de Ciências Criminais (NACCRIM), da \\ Faculdade de Direito de Franca. \\ antoniomiltondebarros@yahoo.com.br
}

\section{RESUMO}

O papel da vítima no processo penal da atualidade deve ser pautado tanto pelas normas de direito internacional como pelas regras internas. No plano internacional, destaca-se a Resolução n. 40/34/85, da ONU. Internamente, destaca-se o art. 245, da Constituição Federal, que prevê assistência jurídica, pelo Poder Público, às vítimas de crime e seus herdeiros. No terreno infraconstitucional, o processo sofreu substancial alteração com o advento da Lei dos Juizados Especiais Cíveis e Criminais (Lei n. 9.099/95), além de outras inovações legislativas que revelam influência da vitimologia. No entanto, o Código de Processo Penal precisa passar por modificações para se adequar a essa tendência.

Palavras-chaves: Constituição Federal - Código de Processo Penal - vítima - ofendido assistente de acusação - reforma processual.

\section{ABSTRACT}

\section{Title: The Role of the Victim in the Penal Law Practice}

The role of the victim in the current penal law practice must be ruled by international law norms as well as by internal ones. On an international basis we can highlight UN Resolution No

40/34/85.

Internally, special emphasis should be placed on chapter 245 from the Federal Constitution, which rules that juridical assistance must be provided by the Government to crime victims and

their

heirs.

Inside the infra-constitutional territory, the process has gone through substantial alteration with the advent of The Special Civil and Criminal Law (Law No 9. 00/95) in addition to other legislative innovations that reveal some influence from the study of victims. However, the Penal Code Practice has to go through some changes in order to adjust to this tendency.

Key-words: Federal Constitution, Penal Code Practice, victim, offended, assistant general attorney, 


\section{Conceito de vítima}

Ofendido ou vítima é a pessoa - física ou jurídica - que suporta os danos decorrentes da infração penal; é o sujeito passivo da infração penal; também considerado sujeito passivo mediato, tendo em vista que o Estado é, sempre, o sujeito passivo genérico e imediato.

Considera-se vítima de crime "toda pessoa física ou jurídica e ente coletivo prejudicado por um ato ou omissão que constitua infração penal, levando-se em conta as referências feitas no conceito de crime pela criminologia” ${ }^{1}$.

Como recorda Alessandra Greco ${ }^{2}$, a doutrina distingue a terminologia conforme a natureza do crime. Assim, a palavra vítima seria para os crimes contra a pessoa; ofendido, para os crimes contra a honra e contra os costumes; lesado, nos crimes patrimoniais; vítima e prejudicado, nos crimes de homicídio, sendo vítima o morto e prejudicado aquele que dependia financeiramente do morto.

Para atuar em juízo, o ofendido precisa ter capacidade processual, que adquire aos 18 anos e desde que não seja mentalmente enfermo ou retardado, conforme disposto nos arts. 33 e 34, do CPP; caso contrário, o direito será exercido por seu representante legal ou curador especial.

\section{Vitimologia: antecedentes históricos, atualidade e perspectivas}

De acordo com Jaume Sole Riera ${ }^{3}$, foi a partir de 1973, quando aconteceu, em Jerusalém, o primeiro Simpósio Internacional de Vitimologia, que começaram a aparecer as primeiras investigações científicas sobre o tema, de forma autônoma, isto é, um tratamento particularizado do assunto, em direção a uma melhor atenção à vítima no processo penal.

Seria, em verdade, uma fase de 'redescobrimento', como analisa Ana Sofia S. Oliveira ${ }^{4}$, porquanto a vítima já tivera maior atenção na Antigüidade, antes de entrar em período de longo esquecimento.

Em 11 de dezembro de 1985, a Assembléia Geral das Nações Unidas adotou a Resolução n. 40/34, em que definiu mais claramente o conceito de vítima e cuidou de fixar os contornos de seus direitos em relação ao processo criminal no que se refere ao dano que tenha suportado.

\footnotetext{
${ }^{1}$ OLIVEIRA, Ana Sofia Schmidt de. A vítima e o direito penal, São Paulo: Revista dos Tribunais, 1999. p. 87

${ }^{2}$ GRECO, Alessandra Orcesi Pedro. A autocolocação da vítima em risco. São Paulo: Revista dos Tribunais, 2004. pp. 17-18

${ }^{3}$ RIERA, Jaume Solé, La tutela de la víctima em el proceso penal. Barcelona: J.M. Bosch, 1997. p. 20.

${ }^{4}$ Op. cit., passim.
} 
Fauzi Hassan Choukr ${ }^{5}$ assevera que essa Resolução evidencia que, para além da necessária proteção, a vítima também deve assumir deveres na nova ordem processual, com maior poder de interferência no destino da ação ou da investigação preparatória.

Com apoio em Delmas-Marty, Choukr assinala que essa é uma tendência de integrar o corpo social à justiça penal, ao mesmo tempo participando, controlando externamente o funcionamento do Estado e comprometendo-se, através de uma conscientização, com a política de repressão às infrações praticadas, sem deixar sempre 'para o especialista’ fazê-lo.

E o mesmo autor preconiza um maior engajamento da vítima no controle de arquivamento de inquéritos policiais, que atualmente se faz apenas nos planos interno e hierárquico, de conformidade com o art. 28, do CPP.

Todavia, o que se procurou fazer, no Brasil como em outros países, em nome de uma alegada preocupação com a vítima, foi agravar a situação dos acusados, inclusive com desrespeito a garantias constitucionais, que além de não atenderem à expectativa de proteção da vítima, colocam em risco importantes conquistas do Estado democrático de direito ${ }^{6}$.

Assim é que, ao impacto de graves ocorrências criminais, com ampla repercussão na mídia em virtude da condição social das vítimas, o legislador editou leis mais severas, de que são exemplos, no Brasil, dentre outras, as Leis 8.072/90 e 8.930/94, a primeira instituindo a Lei dos Crimes Hediondos e a segunda ampliando-lhe o rol, na linha preconizada pelo chamado movimento da Lei e da Ordem, mas que não repercutiram em favor das vítimas, porque não consideram outros reflexos decorrentes do crime, como, por exemplo, no que respeita ao aspecto de reparação do dano.

\section{A vítima no direito processual brasileiro}

No direito processual brasileiro, há distinção entre o interesse particular da vítima pela reparação do dano, e o interesse penal.

Essa separação não é absoluta, porquanto existe a possibilidade de ajuizamento de ação por iniciativa privada, além da influência da decisão condenatória na reparação do dano, mediante sua execução, sem necessidade de novo processo de conhecimento perante o juízo cível (CPP, art. 63).

\footnotetext{
${ }^{5}$ CHOUKR, Fauzi Hassan. Processo penal à luz da Constituição, Bauru: Edipro, 1999. p. 76

${ }^{6}$ OLIVEIRA, Ana Sofia Schimidt, op. cit., p. 127
} 
É importante lembrar que o Direito Penal prevê várias medidas que revelam preocupação com a vítima, consistentes em estimular a indenização como forma de obtenção de benefícios legais, tais como o sursis (CP, art. $78 \S 2^{\circ}$ ), o livramento condicional (CP, art. 83, IV), a reabilitação criminal (CP, art. 94, III) ou a diminuição da pena (CP, art. 16).

Entretanto, a vítima não encontra maior espaço de proteção de seus interesses particulares, como sujeito processual, pois ao Estado interessa precipuamente a apuração do fato sob a perspectiva criminal, em cujo contexto aquela aparece como objeto de prova, dando seu 'testemunho' do crime ou submetendo-se a exame de corpo de delito, conforme o caso; mas, de qualquer modo, não recebendo adequadas informações sobre o andamento do processo e, muitas vezes, sequer sobre seu resultado.

Resta para a vítima a possibilidade de habilitar-se como assistente do Ministério Público para, só assim, ser informada sobre o andamento do processo, não tendo repercutido na prática o comando do art. 245, das Disposições Gerais da Constituição Federal: “A lei disporá sobre as hipóteses e condições em que o Poder Público dará assistência aos herdeiros e dependentes carentes de pessoas vitimizadas por crime doloso, sem prejuízo da responsabilidade civil do autor do delito”, cuja redação teria sido influenciada pelo movimento vitimológico.

Esse quadro processual foi alterado substancialmente com o advento da Lei dos Juizados Especiais Cíveis e Criminais (Lei n. 9.099, de 26/09/1995), que a par de instaurar novo modelo de justiça criminal, baseado no consenso, conferiu à vítima papel de destaque na resolução do caso.

Ainda podem ser assinaladas outras inovações legislativas ocorridas no Brasil, que, segundo a doutrina, também revelam influência da vitimologia:

I. A Lei n. 9.249/95, que criou causa extintiva da punibilidade de determinados delitos, decorrente da reparação do dano antes do recebimento da denúncia;

II. A Lei n. 9.503/97 (alterada pela Lei n. 9.602/98) - Código de Trânsito Brasileiro, que instituiu a multa reparatória;

III. A Lei n. 9.605/98, que prevê a pena de prestação pecuniária e oferece incentivos para a reparação do dano;

IV. A Lei n. 9.714/98, que alterou dispositivos do Código Penal e introduziu a pena de prestação pecuniária.

V. $\quad$ A Lei n. 9.807/99, que trata da proteção a vítimas e testemunhas ameaçadas. 


\subsection{A lei de proteção a vítimas e testemunhas}

De todas essas modificações, talvez a de maior importância seja a Lei n. 9.807, de 13 de julho de 1999, que criou o Sistema Nacional de Proteção a Vítimas e Testemunhas, regulamentada pelo Decreto n. 3.518, de 20 de julho de 2000.

Este programa é gerenciado pela GAVTA - Gerência de Assistência a Vítimas e Testemunhas ameaçadas, cuja atividade principal consiste em apoiar a criação de programas equivalentes nos Estados, mediante convênio com a Secretaria de Direitos Humanos, do Ministério da Justiça, que Coordena o Programa Nacional de Direitos Humanos.

De outro lado, sob a inspiração do Programa Nacional, o Governo do Estado de São Paulo promoveu a elaboração do Programa Estadual de Direitos Humanos (PEDH), com a participação de centenas de entidades da sociedade civil e aprovado pelo Decreto n. 42.209, de 15 de setembro de 1997. Esse mesmo texto criou uma Comissão formada por representantes da sociedade civil e do Governo com a atribuição de acompanhar e incentivar a implementação do Programa.

O Programa estadual incentiva e apóia diversas iniciativas de âmbito municipal, uma das quais consubstanciou-se na criação do CRAVI - Centro de Referência e Apoio à Vítima, um programa da Secretaria da Justiça e Defesa da Cidadania em parceria com diversas instituições e organizações não governamentais, com a finalidade de dar assistência jurídica e psicossocial a vítimas de crimes e seus familiares.

\subsection{A vítima no projeto de reforma do Código de Processo Penal}

Outro tratamento deverá ser dispensado à vítima, em caso de arquivamento de inquérito policial, com a nova redação do art. 28, do CPP, proposta no anteprojeto encaminhado ao Congresso Nacional no final do mês de novembro de 2000, que prevê a possibilidade de o ofendido apresentar razões contra a proposta de arquivamento, a ser analisada por órgão superior da instituição ministerial.

Como há críticas sobre a viabilidade do sistema proposto, em que o controle do arquivamento deverá ser feito pela própria instituição, outras formas serão estudadas, quem sabe até evoluindo-se para uma nova possibilidade de ação penal subsidiária, o que não é admissível no sistema atual, em caso de homologação do pedido de arquivamento. 
Ademais, outro ponto do projeto de reforma contém disposição expressa a respeito da reparação do dano, que deverá ser apreciado, pelo menos em parte, pelo próprio juiz penal. É o que consta da exposição de motivos da reforma sobre os procedimentos, e particularmente quanto aos efeitos da sentença penal condenatória.

De fato, o art. 387, do CPP, que cuida da sentença penal condenatória, teve acrescido um inciso (VII), estipulando que nela o juiz fixe, desde logo, valor mínimo para reparação dos danos provocados pela infração penal, considerando os prejuízos sofridos pelo ofendido.

E ao art. 63, atinente aos efeitos civis da sentença penal, foi acrescentado o parágrafo único, determinando que, transitada em julgado a referida sentença, a execução pode ser efetuada pelo valor fixado pelo juiz, sem prejuízo da liquidação para apuração do dano efetivamente sofrido.

Desse modo, a vítima poderá ser desde logo satisfeita, embora parcialmente, sem necessidade de aguardar as delongas do processo civil de liquidação da sentença penal ou outro processo de conhecimento, também na esfera extrapenal.

\subsubsection{Lei n. 11.690, de 9 de junho de 2008}

As alterações aos artigos referidos nesse tópico ainda não foram implementadas. Todavia, a Lei n. 11.690, de 09 de junho de 2008, introduziu alguma modificação ao Código de Processo, no que toca ao tratamento dispensado ao ofendido, como será analisado a seguir.

Art. 201. Sempre que possível, o ofendido será qualificado e perguntado sobre as circunstâncias da infração, quem seja ou presuma ser o seu autor, as provas que possa indicar, tomando-se por termo as suas declarações.

$\S 1^{\circ} \mathrm{Se}$, intimado para esse fim, deixar de comparecer sem motivo justo, o ofendido poderá ser conduzido à presença da autoridade.

$\S 2^{\circ} \mathrm{O}$ ofendido será comunicado dos atos processuais relativos ao ingresso e à saída do acusado da prisão, à designação de data para audiência e à sentença e respectivos acórdãos que a mantenham ou modifiquem.

$\S 3^{\circ}$ As comunicações ao ofendido deverão ser feitas no endereço por ele indicado, admitindo-se, por opção do ofendido, o uso de meio eletrônico.

$\S 4^{\circ}$ Antes do início da audiência e durante a sua realização, será reservado espaço separado para o ofendido.

$\S 5^{\circ}$ Se o juiz entender necessário, poderá encaminhar o ofendido para atendimento multidisciplinar, especialmente nas áreas psicossocial, de assistência jurídica e de saúde, a expensas do ofensor ou do Estado.

$\S 6^{\circ} \mathrm{O}$ juiz tomará as providências necessárias à preservação da intimidade, vida privada, honra e imagem do ofendido, podendo, inclusive, determinar o segredo de justiça em relação aos dados, depoimentos e outras informações constantes dos autos a seu respeito para evitar sua exposição aos meios de comunicação.

- Redação anterior: art. 201. Sempre que possível, o ofendido será qualificado e perguntado sobre as circunstâncias da infração, quem seja ou presuma ser o seu autor, as provas que possa indicar, tomando-se por termo as suas declarações. 
- Parágrafo único. Se, intimado para esse fim, deixar de comparecer sem motivo justo, o ofendido poderá ser conduzido à presença da autoridade.

Como se pode ver, na reforma parcial do Código, no capítulo das provas, foi inserido um capítulo versando sobre a condição do ofendido, tendo sido acrescentados cinco parágrafos à redação original do Código de Processo Penal.

São regras que preconizam um melhor tratamento à vitima do crime. Inicia-se pela obrigação de que seja comunicada sobre o andamento do processo, depois se recomenda que lhe seja reservado local separado e, por fim, que se resguarde o necessário sigilo, com vistas à preservação da intimidade.

São medidas que, notoriamente, tendem a minimizar aquelas conseqüências que os criminologistas denominam de vitimização secundária, decorrentes de pouco caso ou de maus tratos infligidos à vítima pelos agentes e funcionários de órgãos policiais.

A reforma se preocupa, ainda, com o espaço que o ofendido tinha com vistas à proteção de seus interesses particulares, como sujeito processual, pois, antes, aparecia no processo apenas como objeto de prova, dando seu 'testemunho' do crime ou submetendo-se a exame de corpo de delito, conforme o caso. Em geral, não recebia adequadas informações sobre o andamento do processo e, muitas vezes, sequer sobre seu resultado, exceto quando se habilitasse como assistente do Ministério Público ${ }^{7}$

Essa nova sistemática decorre de um pensamento implantado com base no 245, das Disposições Gerais da Constituição de 1988, acima referenciado.

É bem verdade que nem sempre se aplaude essa maior participação do ofendido no processo. A esse respeito, escreveu Natalie Ribeiro Pletsch ${ }^{8}$ :

O que se observa na cena processual contemporânea, ou melhor, nas reformas
legislativas, é o retorno da vítima ao jogo (processual). Se já nociva a participação
da vítima no processo, voltada para a indenização cível, posto que poderia ser
assegurada naquela esfera a reparação do dano, a sua intervenção, na prática, não
está dirigida tão-só à constituição do título executivo, mas vingar a lesão sofrida, o
que é justificável pela sua incapacidade de distanciamento e racionalização, como já

\footnotetext{
${ }^{7}$ BARROS, Antonio Milton de Barros. Processo penal segundo o sistema acusatório. Leme-SP: LED, 2000.

${ }^{8}$ PLETSCH, Natalie Ribeiro. Formação da prova no jogo processual penal. São Paulo: IBCCRIM, 2007. p. 97.
} 
referido. A implicação prejudicial deste direcionamento é que contribui para reforçar a acusação e, consequentemente, dar-lhe mais armas do que aquelas das quais a defesa dispõe, Ou seja, agrava-se a situação do acusado que é contemplado com um duplo acusador.

\subsection{A vítima como assistente de acusação}

\subsubsection{Conceito de assistente}

Como se sabe, a vítima pode habilitar-se como assistente do Ministério Público, nas hipóteses em que somente este tem a legitimidade para a propositura da ação, ou seja, na ação penal pública. Recorde-se que o ofendido, algumas vezes - pessoalmente ou por meio de seu representante legal - pode propor a ação penal, nos casos de Ação Penal Privada.

A doutrina distingue as partes processuais em 'necessárias’ e 'contingentes’; aquelas são imprescindíveis, pois sem elas não haverá processo, enquanto que estas têm atuação permitida, mas não obrigatória, no processo: “Entre nós, a única parte contingente é o assistente da acusação. A lei permite sua intervenção no processo, mas, com ou sem assistente, o processo existirá” ${ }^{\text {. }}$

O assistente é o próprio ofendido, seu representante legal ou os sucessores daquele, como prevê o artigo 268, do CPP: “Em todos os termos da ação pública, poderá intervir, como assistente do Ministério Público, o ofendido ou seu representante legal, ou, na falta, qualquer das pessoas mencionadas no artigo 31”. Este último dispositivo reza que: "No caso de morte do ofendido ou quando declarado ausente por decisão judicial, o direito de oferecer queixa ou prosseguir na ação passará ao cônjuge, ascendente, descendente ou irmão”.

\subsubsection{Função do assistente}

Dispõe o artigo 271, do CPP: “Ao assistente será permitido propor meios de prova requerer perguntas às testemunhas, aditar o libelo e os articulados, participar do debate oral e arrazoar os recursos interpostos pelo Ministério Público, ou por ele próprio, nos casos dos artigos 584, § $1^{\circ}$ e $598 ”$.

A natureza da função do assistente é motivo de debate na doutrina. Ou considera-se que ele vai a juízo como auxiliar da acusação e não em defesa de um interesse próprio,

\footnotetext{
9 TOURINHO FILHO, Fernando da Costa. Processo Penal. São Paulo: Saraiva, 2003. p. 509
} 
ficando equiparado ao litisconsorte do Código de Processo Civil ${ }^{10}$, ou que, ao contrário, sua função não é a de auxiliar a acusação, mas a de procurar defender seu interesse na indenização do dano ex delicto ${ }^{11}$.

No entanto, parece-nos que a discussão não se justifica, porquanto os poderes conferidos ao assistente são de molde a possibilitar auxílio, apoio, à atividade do Ministério Público. De outro lado, não se pode negar, e nesse ponto há realmente consenso, que o ofendido habilita-se como assistente com a finalidade de proteger seu interesse, na medida em que o resultado da ação penal poderá lhe servir como base para a reparação do dano. Assim, as duas posições não são excludentes, mas perfeitamente conciliáveis.

Este era o entendimento de Borges da Rosa ${ }^{12}$, que a respeito do tema deixou escrito: “O assistente só em ação pública pode intervir para defender o seu direito, como auxiliar do promotor público".

Por outro lado, ainda que anteriormente pudesse ser discutida a questão, o panorama que se descortina, em relação ao tratamento a ser dado à vítima do crime, há que influir, por coerência, na formação de uma nova mentalidade, também, no que diz respeito às suas atividades processuais quando se habilitar como assistente de acusação.

\section{O papel da vítima no direito comparado}

\subsection{Espanha}

No direito espanhol, a vítima tem participação no processo junto com a acusação oficial, na condição de acusador particular, de acusador popular, ou mesmo quando haja conexão entre interesses primariamente privados e interesse público, cuja ação é proposta pelo Ministério Público, de forma que, no dizer de Riera ${ }^{13}$, não existe um sistema de monopólio acusatório no exercício da ação penal, senão uma situação de concorrência entre o Ministério Público e os particulares, realizada normalmente através da utilização da querela.

A despeito disso, o autor aponta vicissitudes e dissabores por que passam as vítimas de crimes, enfrentando a má vontade, senão mesmo o descaso, de funcionários da polícia, depois

\footnotetext{
10 ESPÍNOLA FILHO, Eduardo, Código de Processo Penal brasileiro anotado. 6. ed., Rio de Janeiro: Borsoi, 1965. p. 269 e FREDERICO MARQUES, José. Elementos de direito processual penal, SILVEIRA, Victor Hugo Machado da (atual.), Campinas: Bookseller, 1997. p. 235.

${ }^{11}$ TOURINHO FILHO, p. cit., p. 514

12 BORGES DA ROSA, Inocêncio. Processo penal brasileiro, Porto Alegre: Globo, 1941. p. 204

${ }^{13}$ RIERA, Jaume Solé, La tutela de la víctima em el proceso penal. Barcelona: J.M. Bosch, 1997. p. 27
} 
novamente em juízo, que significam, não raro, aprofundar a afetação pessoal suportada com o delito.

Ademais, assinala constatar-se uma situação de 'neutralização processual', em vista das escassas oportunidades de tutela e participação efetiva que o processo penal oferece à vítima do delito.

Em suma, a conclusão que se extrai das colocações feitas na obra acima referida, é que a vítima, quando não é a proponente da ação, ou seja, quando não figura diretamente como parte, é ignorada pelo sistema, no sentido de não ser informada sobre o andamento do processo e de não ter acesso aos autos, enfim encontra-se alienada da tutela judicial que, em última análise, lhe interessa tão ou mais de perto do que ao próprio Estado.

Como visto antes, no Brasil não é diferente, no que concerne à desinformação do ofendido, já que não há obrigação legal de se o informar sobre o andamento da ação penal, pese embora ser duplamente interessado, tendo em vista que o resultado da ação penal pode ser utilizado na esfera civil. A diferença reside em que, na lei espanhola, em casos de ação penal pública, o Ministério Público possui legitimidade, também, para a ação civil quando ajuizada conjuntamente com a penal, conforme dispõe o artigo 108, da Ley de Enjuiciamento Criminal.

\subsection{Argentina}

Na Argentina, segundo informa Pedro Bertolino ${ }^{14}$, o Código Nacional, assegura à vitima participação e proteção processual; ela pode ser denunciante (que corresponde ao ato de dar a notícia crime), ou uma das seguintes figuras:

I - querelante particular, que é um substituto processual, mas para um delito de ação pública (e não privada, como no Brasil) e equivale ao nosso assistente de acusação, porquanto, como este, não tem autonomia para ajuizar a ação penal (quando não privada), mas apenas aderir àquela proposta pelo órgão oficial. É certo que, além deste que seria um querelante 'adesivo', existe a figura do querelante 'exclusivo', para os casos de ação privada;

II - 'actor civil', caracterizado como o sujeito secundário e eventual da relação processual, que mediante uma ação civil acessória à penal, deduz a pretensão de ressarcimento com base no mesmo fato que constitue o objeto dessa relação, requerendo uma sentença favorável (tradução livre).

\footnotetext{
${ }^{14}$ BERTOLINO,Pedro J.. Víctima en el Proceso Penal, Buenos Aires: Delpalma, 1997.
} 
III - la víctima 'a secas': aqueles ofendidos que não exercem quaisquer dos papéis referidos, por dificuldades peculiares a cada um; estes, todavia, têm preservados os direitos de proteção e de informação, por parte do Estado, a respeito do processo e seu andamento.

\subsection{Itália}

Na Itália, a vítima tem legitimidade, inclusive, para ingressar na ação penal, como parte contingente, para o fim de obter a reparação do dano, como esclarece o professor da Universidade de Padova, Alfredo Molari ${ }^{15}$ :

O exercício da ação reparatória no processo penal dá lugar à presença nesse da parte civil e às vezes do responsável civil (...) Mas porque se trata justamente de mera eventualidade, e, ademais, no curso de um processo essencialmente penal, estes sujeitos são qualificados como partes acessórias; ou seja - como outros preferem expressar-se - partes secundárias ou, mais precisamente, eventuais (tradução livre).

Portanto, a possibilidade de cumulação de jurisdições - penal e civil -, na Itália, é facultativa, como também confirma Antonio Scarance Fernandes ${ }^{16}$.

\subsection{Portugal}

O Código de Processo Penal português (Dec. Lei n. 78/87, de 17 de fevereiro), também, prevê a possibilidade de o ofendido habilitar-se como assistente, no Processo Penal, a cuja figura reporta-se nos artigos 68 a 70, indicando os ofendidos dentre as pessoas que podem constituir-se como tal.

Além disso, dispõe o estatuto processual luso que o pedido de indenização civil fundado na prática de crime, em regra, é deduzido no Processo Penal respectivo, conforme artigo $71^{\circ}$, só podendo ser formulado perante o tribunal civil excepcionalmente, nos casos elencados no dispositivo subseqüente. Assim, a forma usual para a reparação do dano ex delicto é o da cumulação ou união obrigatória, em regra.

\section{Conclusão}

Como visto, já existem algumas previsões formais e mesmo modificações legislativas que revelam uma maior preocupação com a vítima de crimes. Resta, contudo, a implementação dessas garantias, de modo especial aquela que permite a efetividade de acesso à justiça, para que a vítima possa assumir outros deveres processuais e, assim, tenha seu direito assegurado plenamente.

\footnotetext{
${ }^{15}$ MOLARI, Alfredo. Manuale di Procedura Penale. 2. ed. Bologna: 1997. p. 115.

16 O papel da vítima no Processo Criminal. São Paulo: Malheiros, 1995. p. 65
} 
No aspecto legislativo, a maior expectativa está na reforma mais ampla do Código de Processo Penal, tendo em vista que os atores processuais geralmente aguardam que a Constituição Federal seja regulamentada, mesmo quando os dispositivos constitucionais dispensem tal providência.

No entanto, mais do que as mudanças na lei e a criação de novos instrumentos formais, impõe-se uma mudança de postura e de mentalidade, tanto do poder público, como de todos os cidadãos, para a implementação efetiva das garantias já previstas e daquelas em fase de regulamentação.

\section{Referências bibliográficas}

ANTUNES, Maria João. Código de processo penal português, Coimbra: Coimbra, 1998.

BERTOLINO, Pedro B. e al. La víctima en el proceso penal. Buenos Aires: Delpalma, 1997.

BARROS, Antonio Milton de. A lei de proteção a vítimas e testemunhas. 2. ed. Franca-SP: Lemos \& Cruz, 2006.

. Curso básico de processo penal. Franca-SP: Lemos \& Cruz, 2007.

BORGES DA ROSA, Inocêncio. Processo penal brasileiro, Porto Alegre: Globo, 1941.

CATENA, Victor Moreno. Ley de enjuiciamiento criminal. Madri: Tecnos, 1998.

CHOUKR, Fauzi Hassan. Processo penal à luz da Constituição, Bauru: Edipro, 1999.

DELMAS-MARTY, Mireille. Modelos e movimentos de política criminal. Trad. Edmundo Oliveira, Rio de Janeiro: Revan, 1992.

ESPÍNOLA FILHO, Eduardo, Código de Processo Penal brasileiro anotado. 6. ed., Rio de Janeiro: Borsoi, 1965.

FERNANDES, Antonio Scarance. Processo penal constitucional. São Paulo: Revista dos Tribunais, 1999.

. O papel da vítima no Processo Criminal. São Paulo: Malheiros, 1995.

FREDERICO MARQUES, José. Elementos de direito processual penal, SILVEIRA, Victor Hugo Machado da (atual.), Campinas: Bookseller, 1997.

GRECO, Alessandra Orcesi Pedro. A autocolocação da vítima em risco. São Paulo: Revista dos Tribunais, 2004.

MOLARI, Alfredo. Manuale di Procedura Penale. 2. ed. Bologna: 1997.

OLIVEIRA, Ana Sofia Schmidt de. A vítima e o direito penal, São Paulo: Revista dos Tribunais, 1999.

PISAPIA, Gian Domenico. Compendio de procedura penale, 2. ed, Padova: Cedam, 1979 
PISANI, Mario. MOLARI, Alfredo. PERCHINUNNO, Vincenzo. e CORSO, Piermaria. Manuale di procedura penale, $2^{\mathrm{a}}$ ed., Bologna, Itália: Monduzzi, 1997.

PLETSCH, Natalie Ribeiro. Formação da prova no jogo processual penal. São Paulo: IBCCRIM, 2007. p. 97.

RIERA, Jaume Solé, La tutela de la víctima em el proceso penal. Barcelona: J.M. Bosch, 1997.

SÃO PAULO. (Estado). SECRETARIA DA JUSTIÇA E DA DEFESA DA CIDADANIA. Direitos Humanos e Cidadania nos Municípios. 2. ed., 2.000.

TOURINHO FILHO, Fernando da Costa. Processo penal. 25 ed., São Paulo: Saraiva, 2003. 